\title{
Editorial
}

\section{Making a difference in breeding science}

World prices for most staple crops are soaring at an unexpected rate. For example, the market price of rice, wheat, corn and soybean has increased 2.5-fold, 1.9-fold, 1.6-fold, and 1.8-fold, respectively, from April 2007 to April 2008. Such rapid increase in prices of main staples has never occurred since the success of the so-called Green Revolution. In addition, the global stocks of these crops are at their lowest in 20 years. This crisis has been brought about partly due to emerging demand for alternative fuels such as ethanol and the worldwide movement to reduce $\mathrm{CO}_{2}$ efflux from fossilderived fuel like petroleum and coal. In Brazil, although sugarcane has long been used as source of ethanol for fuel, the market price remains stable mainly because it is not a main staple food. The situation is very much different in the US where corn is used as a source of ethanol. Corn is more commonly used as a starting material for ethanol because fermentation of corn is a very simple process. In addition, US corn farmers are happy with this turn of events because their produce can fetch much higher market price as compared to selling corn for use as feed for livestock. As a result, other crops are relegated because many farmers shifted to planting corn on land previously used for other crops. This trend will continue to influence not only the prices of major crops but also the circle of flow of carbon resources including crops and petroleum. Furthermore, the use of food as a source of fuel may have serious implications that may result in a global food crisis.

Such scenario is already expected considering the fragile balance of consumption and production of staple foods in the world. Even if the increasing demand for biofuels is taken out of the equation, problems such as an ever-growing world population, rapid deterioration of the quality of soil and water that support crop production, and drastic changes in the climatic conditions of the earth has been threatening human survival. This should require scientists in various fields, particularly the plant researchers and breeders, to join forces in finding a solution to a major catastrophe facing humankind. And expectations continue to grow as more attention is being accorded to the contributions of scientific research through the mass media. Some of the most publicized outputs in rice research for example, include the identification of a gene contributing to major QTL of seed width of rice and the genes involved in arsenite transport in rice roots. It is interesting to note that our colleagues at the Japanese Society of Breeding authored both of these studies. As a scientific organization, we are very proud of these achievements, which in a way also reflect our role for further advancement of agricultural research.

There is no doubt however that many scientists and researchers would equate the merit of a research on the status of the journal to which it is published. Basically, the quality of a science journal is measured by the statistical score, impact factor (IF), as summarized by Thomson Scientific. It is the most objective index to gauge a journal calculated on a three-year period based on the number of citations in a year. The latest IF of Breeding Science is 1.079, an increase of 0.457 from the previous year. This increase is undoubtedly due to the publication of high-quality articles in the last two years as well as the increasing concern in elucidating the many aspects of crop production. Although a scientific journal's impact factor is important, we must always remember that it is merely an objective measure of the way a published article is perceived and evaluated. The real merit of a research article can only be measured on how a particular result or output has made an impact in clarifying certain biological phenomena and solving the major problems we are facing today. So as plant breeders and researchers, we must always strive to make contributions focusing on the importance of plant breeding to solve problems on food, environment and energy, while at the same time making new discoveries in the area of basic science.

Takuji Sasaki Editor-in-Chief National Institute of Agrobiological Sciences 
